\title{
THE BEHAVE APPLICATION: AN EVIDENCE-BASED TOOL TO MANAGE SOCIAL EMOTIONAL BEHAVIOURAL DIFFICULTIES
}

\author{
Gianluca Merlo1, Giuseppe Chiazzese ${ }^{1}$, Alberto Mirisola², Isabella Giammusso², \\ Manuela Sanches-Ferreira ${ }^{3}$, Sebastian Bilanin ${ }^{4}$, Colin McGee ${ }^{5}$, Nicola Lo Savio ${ }^{6}$, \\ Melanie van Oort-Hall ${ }^{7}$ \\ 1/stituto per le Tecnologie Didattiche, Consiglio Nazionale delle Ricerche (Italy) \\ ${ }^{2}$ Department of Psychological, Pedagogical and Educational Sciences, University of \\ Palermo (Italy) \\ ${ }^{3}$ School of Education, Polytechnic Institute of Porto (Portugal) \\ ${ }^{4}$ Fundatia de Abilitare Speranta (Romania) \\ ${ }^{5}$ National Attention Deficit Disorder Information and Support Service (United Kingdom) \\ ${ }^{6}$ Istituto Tolman (Italy) \\ ${ }^{7}$ UC Leuven-Limburg (Belgium)
}

\begin{abstract}
Social Emotional and Behavioural Difficulties (SEBD) are a persistent and multiple manifestation of maladaptive behaviours which interfere with the students' learning, social functioning and development and/or that of their peers. They may become apparent through withdrawn, passive, aggressive or self-injurious tendencies. The prevalence of these disorders is $2-16 \%$ of the general population. Children with SEBD, diagnosed or not, are likely to live in social isolation, to receive a poor education, and they risk becoming deviant teenagers, or unemployed adults. A way to approach SEBD with consistent level of educational success is to equip teachers with proper training on practical and proven classroom management strategies, but also with evidence-based tools that can help them to effectively control difficult behaviours with confidence and competence. This contribution presents the web-based BEHAVE application aimed to ease the way for teachers to apply behavioural evidence-based interventions at school. The paper describes the main features of the BEHAVE application: the definition of the behaviour to be observed, the creation and selection of appropriate measures, the collection of behavioural data, and the statistical analysis to evaluate the direction and the power of the effect of the carried-out intervention.
\end{abstract}

Keywords: Social Emotional and Behavioural Difficulties, evidence-based, problematic behaviours, behavioural interventions, school education.

\section{INTRODUCTION}

Behaviourally taxing students are one of the most widespread concerns of teachers across the world. In a theoretical framework the child with social, emotional and behavioural difficulties (SEBD) can be identified as a student that adults and other students experience as disruptive and/or disturbing. This group are also frequently seen as interfering with other students' learning, their social functioning and development [1]. In the school setting, "emotional and behavioural difficulties range from social maladaptation to abnormal emotional stresses. They are persistent (if not necessarily permanent) and represent significant learning difficulties and differences. They may be multiple and may manifest themselves in many different forms and severities. They may become apparent through withdrawn, passive, aggressive or self-injurious tendencies" [2]. It is quite clear that many children and young people to whom the term is applied have complex and chronic difficulties such as problems in social competence, peer rejection, academic underachievement, high rates of school drop-out. They will also tend to internalise problems as anxiety and/or withdrawal, which in turn place them at risk of academic failure and wider social exclusion [3]. Viewed from a cognitive-behavioural perspective, the problematic behaviours are constantly and closely linked to the environment. In fact, despite knowing that SEBD are biologically rooted, the ways in which the biological factors affect behaviour is always mediated by the interaction with the many different environments around the person. From this perspective, defined biopsychological, teachers and educational staff play a crucial role in determining and understanding the effects of the student's condition on their current behaviour and educational 
engagement. In order to enable the SEBDs student to experience a consistent level of educational success it is vital to improve the educators' recognition and understanding of problems. We also need to support them in identifying and applying specific and appropriate 'scaffolding' or adjustments to the school environment by encouraging them to understand and improve their teaching styles and approaches to meet the constantly emerging and ever-changing challenges as and when they arise. Without the appropriate knowledge of the different theories and methodologies that are the basis of most of the effective evidence-based practices for managing SEBDs, teachers will become limited in their professional efficacy and increasingly unable to cope with on-going and emergent problematic situations. They will develop high personal levels of stress and burnout $[4,5]$. Literature reports that $50 \%$ of teachers (of all levels of school teaching) are spending more time with problem behaviour management than they would like [6], and that among them exists a profound feeling of ineffectiveness in the implementation of behavioural strategies [7]. With the aim of supporting teachers to respond both constructively and effectively to students who present with SEBDs, we would like to introduce the BEHAVE application. This is a web-based tool designed to enable teachers to apply evidence-based behavioural interventions in school. The BEHAVE application it is suitable for both a large range of neurodevelopmental disorders and more specifically for children with SEBD. We fully expect that the long-term effect of this will be to promote the improved quality of teaching and foster better learning opportunities for students.

\section{THE BEHAVE APPLICATION}

The development of the BEHAVE application was inspired to the WHAAM application produced during the WHAAM project $[8,9,10,11,12]$. The WHAAM application supports parents, teachers, and health professionals in the effective management of undesired ADHD behaviours. The WHAAM application users can create a virtual network of people who are significant for the ADHD child in their main life contexts (for instance home and school) in order to share knowledge and relevant information about the child's behaviours between themselves. Moreover, the network can gather data to make a hypothesis about the function of a child's behaviour and to plan, with the help of a health professional, a behavioural intervention to reduce or eliminate the inappropriate behaviour.

While the original WHAAM application had a identified focus on the management of ADHD students challenging behaviours, the BEHAVE application has been designed to be more flexible and be adaptable to cover a wide range of neurodevelopmental disorders and professional practices. In particular, the following table (Table 1) describes the differences between the WHAAM and the BEHAVE applications:

Table 1. Comparison table between the features of WHAAM and BEHAVE applications.

\begin{tabular}{l|c|c}
\hline \hline & WHAAM & BEHAVE \\
\hline $\begin{array}{l}\text { Suitable for many } \\
\text { neurodevelopmental } \\
\text { disorders }\end{array}$ & NO & YES \\
\hline Custom measures & NO & YES \\
\hline $\begin{array}{l}\text { Multiple single case } \\
\text { design }\end{array}$ & NO & YES \\
\hline $\begin{array}{l}\text { Calculation of the } \\
\text { TAU U index }\end{array}$ & YES & YES \\
\hline $\begin{array}{l}\text { Calculation of the } \\
\text { Allison and Gorman } \\
\text { index }\end{array}$ & NO & YES \\
\hline Responsive design & NO & YES \\
\hline Open data & NO & YES \\
\hline \hline
\end{tabular}




\subsection{Architecture}

The BEHAVE application is based on a client-server architecture (Figure 1). The clients (web browsers) are connected to the Apache/httpd application server running the PHP framework Symfony on top of a MySQL and a CouchDb databases. The client frontend has been developed using the Bootstrap framework that make it easier to develop responsive application adaptable to any screen size. The module RApache [13] is installed on the Apache web server to analyse the datasets collected by the users.

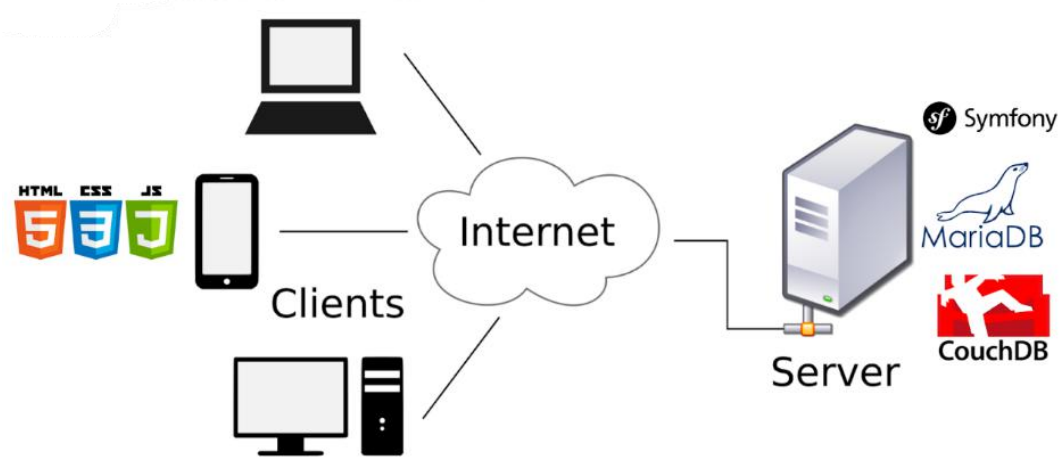

Figure 1. Architecture and main technologies used during for the development of the BEHAVE application.

\subsection{Features}

A user account has to be created in order to use the BEHAVE application. Users can choose to register a new account or using an existing Google, Facebook, or Twitter account. The BEHAVE application supports in fact the OAuth 2.0 protocol [14], the standard strategy to support a universal login system.

The following are the main BEHAVE features, starting from the insertion of a student, the creation of a measure, and the process of data gathering and the related ensuing analysis.

\subsubsection{Student creation}

A student's name must be inserted to start the behavioural monitoring process (Figure 2). Students are characterized by id's or nicknames to guarantee the safety of pupils' personal data. Other optional information requested by the application are the year of birth, the sex, the disorders of which they are diagnosed with and any comorbidities or co-existing conditions. 


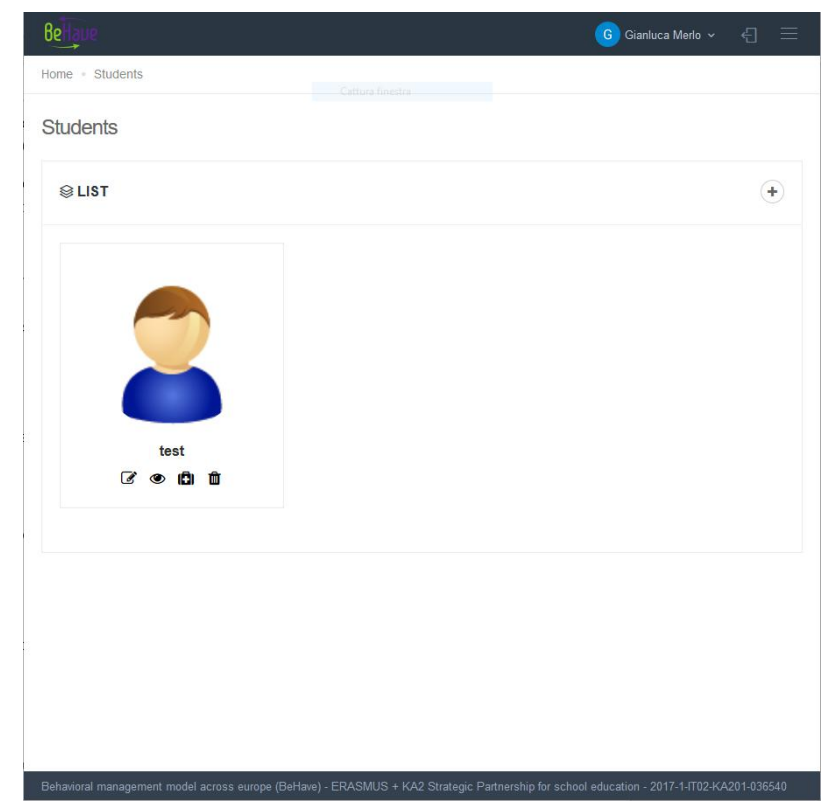

Figure 2. Screenshot of the student section.

\subsubsection{Measure creation}

The BEHAVE application includes a set of tools for the creation of the customized measures described in Table 2 and represented in Figure 3:

Table 2. Description of the widgets for the creation of the measures.

\begin{tabular}{l|c|c}
\hline $\begin{array}{l}\text { Widget } \\
\text { typology }\end{array}$ & Description & Validation rules \\
\hline Choice & $\begin{array}{c}\text { The widget creates } \\
\text { a radio buttons and } \\
\text { a selection process. } \\
\text { Multiple selections } \\
\text { of values are } \\
\text { allowed. }\end{array}$ & $\begin{array}{c}\text { The values sent } \\
\text { from the form have } \\
\text { to be the same as } \\
\text { those included in } \\
\text { the lists. }\end{array}$ \\
\hline Duration & $\begin{array}{c}\text { The widget is } \\
\text { designed to } \\
\text { measure the } \\
\text { duration of a } \\
\text { phenomenon. }\end{array}$ & $\begin{array}{c}\text { The values sent } \\
\text { from the form have } \\
\text { to be in the } \\
\text { timestamp format. }\end{array}$ \\
\hline Frequency & $\begin{array}{c}\text { The widget is aimed } \\
\text { to count the } \\
\text { occurrences of a } \\
\text { phenomenon. }\end{array}$ & $\begin{array}{c}\text { The values sent } \\
\text { from the form have } \\
\text { to be in the } \\
\text { timestamp format. }\end{array}$ \\
\hline Integer & $\begin{array}{c}\text { The widget is aimed } \\
\text { at supporting the } \\
\text { creation of items } \\
\text { with a numeric } \\
\text { response. }\end{array}$ & $\begin{array}{c}\text { The value sent from } \\
\text { the form has to be } \\
\text { an integer. }\end{array}$ \\
\hline $\begin{array}{l}\text { Four } \\
\text { quadrant }\end{array}$ & $\begin{array}{c}\text { The widgets is } \\
\text { intended to create a }\end{array}$ & $\begin{array}{c}\text { The values sent } \\
\text { from the form are 2 }\end{array}$ \\
\hline \hline
\end{tabular}




\begin{tabular}{l|c|c}
\hline \hline diagram & $\begin{array}{c}\text { cartesian plane. The } \\
\text { user has to select } \\
\text { the point in the } \\
\text { plane where he } \\
\text { feels to belong } \\
\text { according to the } \\
\text { predefined } \\
\text { categories. }\end{array}$ & $\begin{array}{c}\text { integers, } 1 \text { for the } x \\
\text { axis and } 1 \text { for the } y \\
\text { axis. }\end{array}$ \\
\hline Range & $\begin{array}{c}\text { The widget is } \\
\text { intended to create } \\
\text { an input with a } \\
\text { numeric value which } \\
\text { must be no less } \\
\text { than a given value, } \\
\text { and no more than } \\
\text { another given value. }\end{array}$ & $\begin{array}{c}\text { The value sent from } \\
\text { the form is included } \\
\text { in the planned } \\
\text { range. }\end{array}$ \\
\hline Text & $\begin{array}{c}\text { The widget is } \\
\text { intended to create a } \\
\text { textual input. }\end{array}$ & $\begin{array}{c}\text { The value sent from } \\
\text { the form must be a } \\
\text { textual type. }\end{array}$ \\
\hline \hline
\end{tabular}

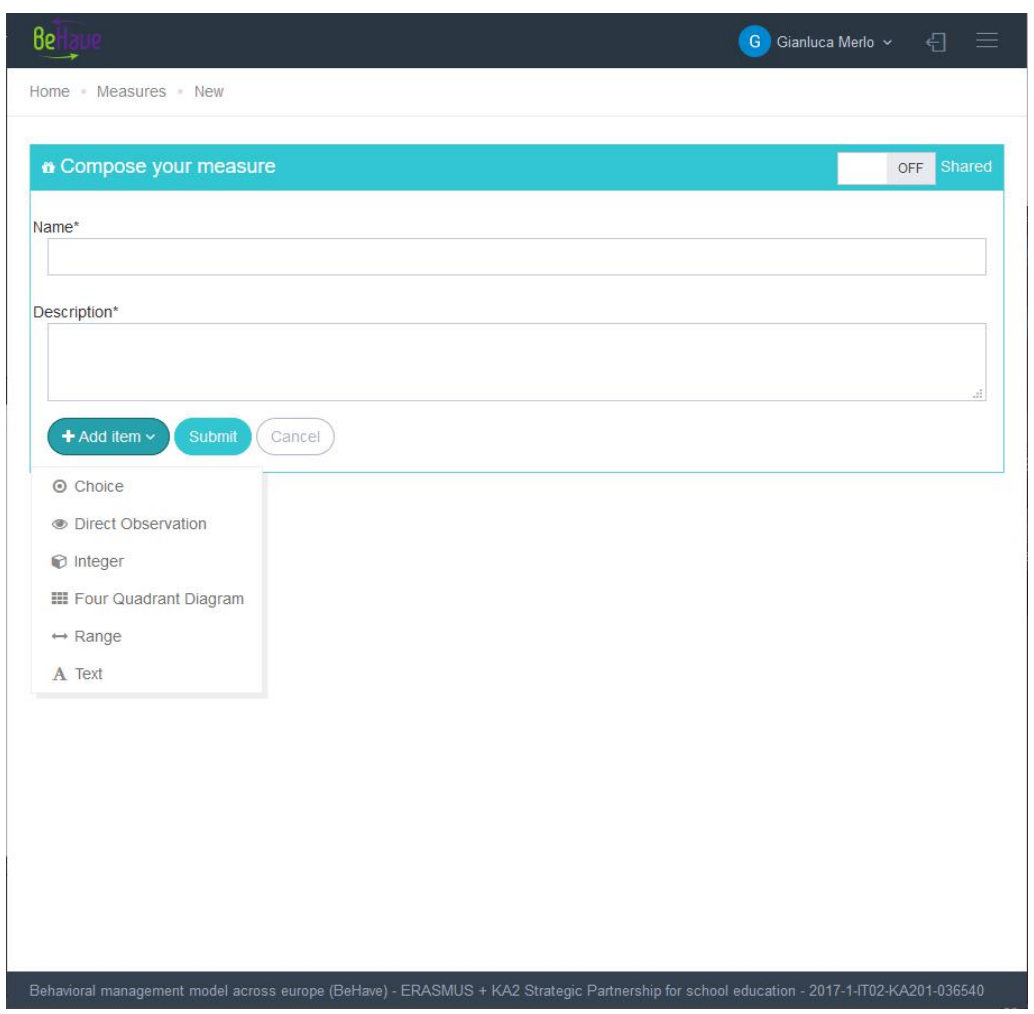

Figure 3. Screenshot of the measure creation.

\subsubsection{Planning of the observation}

Once the user completes the measure with the widgets provided by the application, they must decide which is the behaviour to work on. The behaviour has to be defined according to an operational definition (Figure 4): the user has to describe the behaviour in a specific way that makes it possible to identify the same behaviour when observed by different people, even when it occurs in very different settings. Moreover, users can add information about the place and the setting in which the behaviour occurs. Users can choose how often they want the observation to repeat, and when they want the 
repeating event to end. According to these settings the system automatically adds the events in a calendar. The date or hour of an event can be edited if needed.

The user can copy the URL of the page in which data will be gathered or insert the email addresses of the observers that will receive a notification via email to remind them to collect the data at the right time.

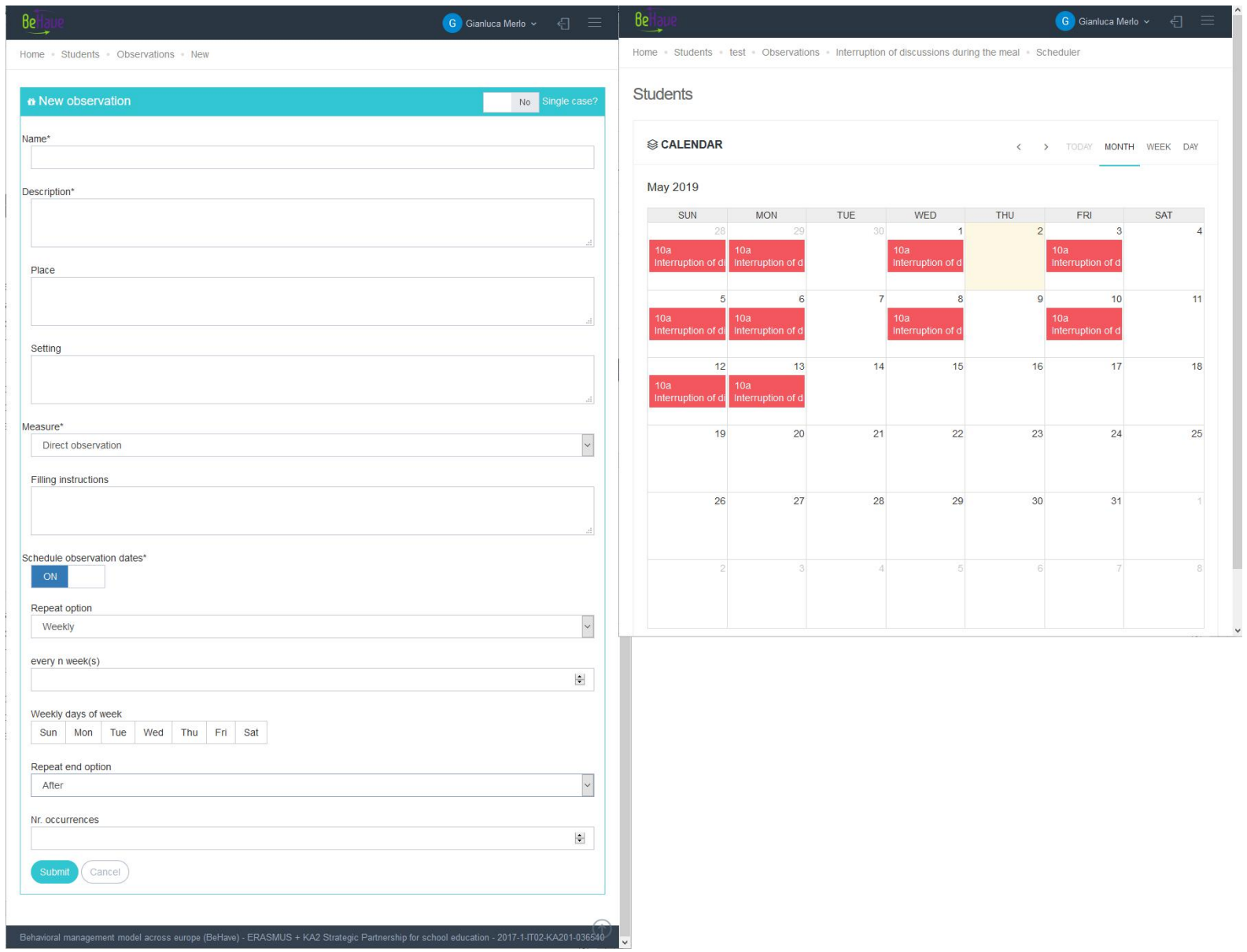

Figure 4. Screenshot of the form to plan an observation and the related calendar.

\subsubsection{Data collection}

The data collection phase consists of the moment when the observer gathers the data of a behaviour from a context, according to the measure previously created, the planned date and the time preferences.

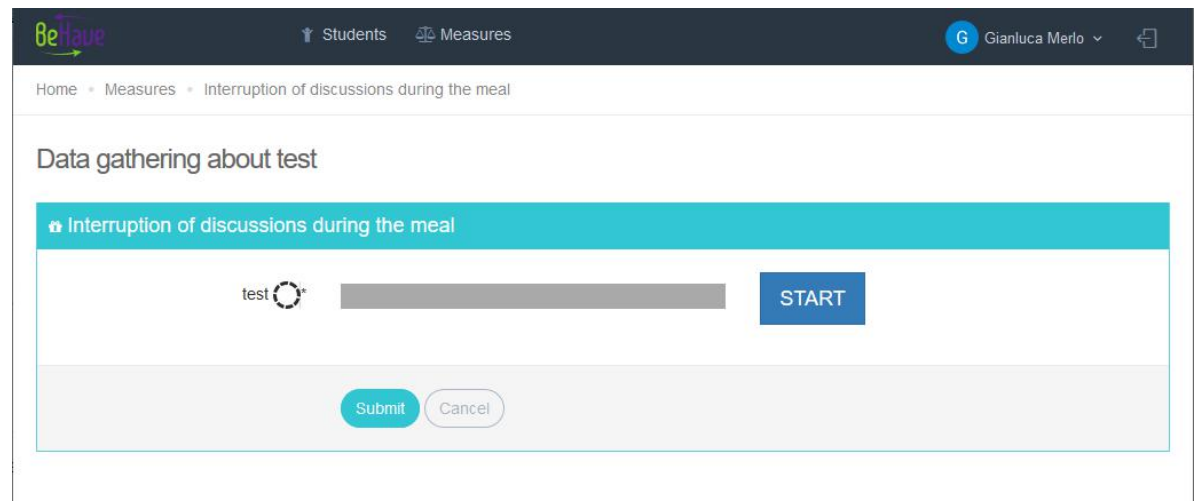


Figure 5. Screenshot of interface to gathered information about the duration of a behaviour.

\subsubsection{Data analysis}

If the measure is feasible for a single case design, the user who created the measure will be able to label the gathered data according to the phase of the research to which they belong. If the data is composed by at least 2 phases and at least 4 observations, the dataset will be analysed to assess the effect size of the applied intervention. A Montecarlo simulation is used to select the best statistical algorithm to use for the collected dataset. The BEHAVE application supports the Allison and Gorman [15] and Parker et al.'s [16] approaches: the first assumes a parametric linear trend, whereas the second assumes a non-parametric monotonic trend. Items can be aggregated by the calculation of a sum or a mean.

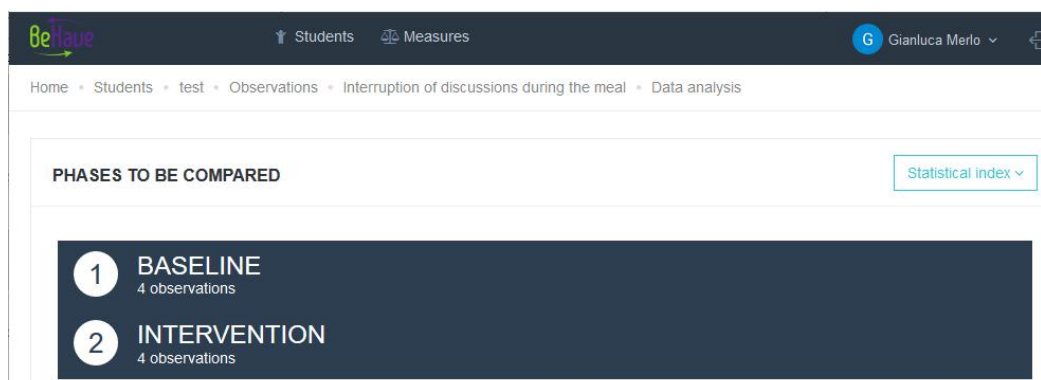

ITEMS TO BE ANALYZED

\section{TEST}

SCATTER PLOT

Interruption of discussions during the $\equiv$ meal

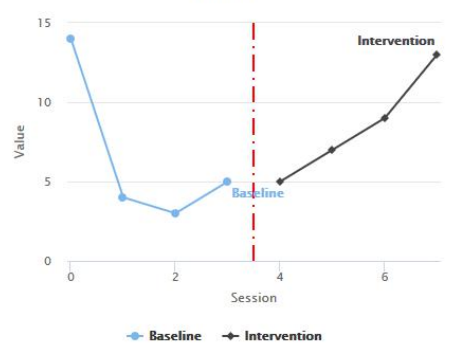

PARKER'S TAU-U Partition and Full Matices

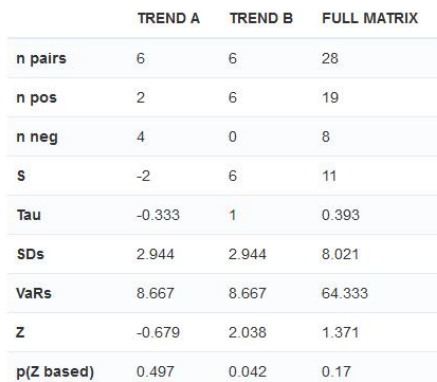

SPEEDOMETER: AVSB+TRENDB

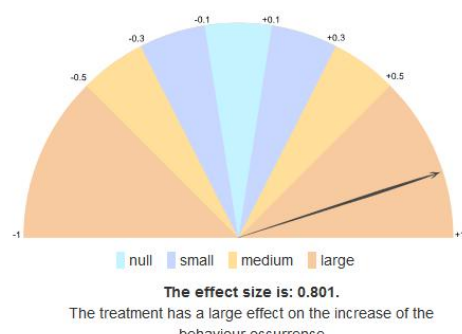

\begin{tabular}{llll} 
& A vs B & $\begin{array}{l}\text { A vs B + } \\
\text { TREND B }\end{array}$ & $\begin{array}{l}\text { A vs B + TREND B - } \\
\text { TREND A }\end{array}$ \\
\hline n pairs & 16 & 22 & 28 \\
\hline$n$ pos & 11 & 17 & 21 \\
\hline $\mathbf{n}$ neg & 4 & 4 & 6 \\
\hline $\mathbf{S}$ & 7 & 13 & 15 \\
\hline Tau & 0.438 & 0.591 & 0.536 \\
\hline SDs & 6.887 & 7.475 & 8.021 \\
\hline VaRs & 47.429 & 55.881 & 64.333 \\
\hline $\mathbf{Z}$ & 1.016 & 1.739 & 1.87 \\
\hline
\end{tabular}

Figure 6. Screenshot of the data analysis section. 


\section{CONCLUSIONS}

The BEHAVE application is the main outcome of the BEHAVE Erasmus+ project aimed to reinforce and enlarge networks and to promote a transnational culture about some of the most effective strategies to approach SEBDs in classroom. The BEHAVE application offers to teachers and educational staff a tool for managing SEBDs in a more systematic way. The system represents an example of evidence-based tool for enhancing the management of behavioural problem facilitating and reducing the time of the data collection usually done by hand and introducing statistical evidence features for evaluating the effectiveness of an intervention [17]. Literature demonstrates that evidencebased procedures of behavioural assessment allows educators to identify and speed up the signs of neurodevelopmental disorders in a preventive perspective soliciting early interventions. The wellbeing of children strongly depends on well-timed interventions and the school plays a crucial role in the development of the future adults. For this reason, the project includes a training mobility program with the aim to empower teacher's professional profile of primary schools who are daily involved in a set of activities to guarantee a better quality of life to SEBD students.

\section{ACKNOWLEDGEMENTS}

The BEHAVE application is one of the main results of the Behavioral management model across Europe (BEHAVE) project funded under the Erasmus+ programme (KA2 Strategic Partnership for school education, reference number: 2017-1-IT02-KA201-036540).

\section{REFERENCES}

[1] C. Cefai, and P. Cooper, P., "Students without voices: the unheard accounts of secondary school students with social, emotional and behaviour difficulties", European Journal of Special Needs Education, vol. 25, no. 2, pp. 183-198, 2010.

[2] Department for Education and Employment (DfEE), "The Education of Children with Emotional and Behavioural Difficulties”, Circular 9/94, London: DFE, 1994.

[3] S. S. Riney, and L. M. Bullock, "Teachers' perspectives on student problematic behavior and social skills", Emotional and Behavioural Difficulties, vol. 17, no. 2, pp. 195-211, 2012.

[4] A. Brouwers, and W. Tomic, "A longitudinal study of teacher burnout and perceived self-efficacy in classroom management", Teaching and Teacher education, vol. 16, no. 2, pp. 239-253, 2000.

[5] R. P. Hastings, and M. S. Bham, "The relationship between student behaviour patterns and teacher burnout". School Psychology International, vol. 24, no. 1, pp. 115-127, 2003.

[6] R. Beaman, K. Wheldall, and C. Kemp, "Recent Research on Troublesome Classroom Behaviour: A Review", Australasian Journal of Special Education, vol. 31, no. 1, pp. 45-60, 2007.

[7] W. M. Reinke, M. Stormont, K. C. Herman, R. Puri, and N. Goel, "Supporting children's mental health in schools: Teacher perceptions of needs, roles, and barriers", School Psychology Quarterly, vol. 26, no. 1, 2011.

[8] D. Spachos, A. Chifari, G. Chiazzese, G. Merlo, G. Doherty, and P. Bamidis, "WHAAM: A mobile application for ubiquitous monitoring of ADHD behaviors", International Conference on Interactive Mobile Communication Technologies and Learning, pp. 305-309, 2014.

[9] G. Merlo, G. Chiazzese, O. Di Giuseppe, and D. Spachos, "Monitoraggio comportamentale a scuola e in famiglia: I'applicazione WHAAM", Italian Journal of Educational Technology, vol. 24, no. 1, pp. 47-51, 2016.

[10] L. Seta, A. Chifari, and P. Denaro, P., "Il progetto WHAAM: un servizio per genitori e insegnanti di studenti con ADHD", Italian Journal of Educational Technology, vol. 24, no. 1, pp. 56-60, 2016.

[11] S. Alves, P. Bamidis, A. Bilbow, A. Callahan, G. Chiazzese, A. Chifari, ... and N. Myttas, "WHAAM: Context-Driven Framework", WHAAM: Context-Driven Framework, pp. 1-148. 
[12] G. Merlo, G. Chiazzese, M. Sanches-Ferreira, A. Chifari, L. Seta, C. McGee, ... and I. Giammusso, "The WHAAM Application: A Tool to Support the Evidence-Based Practice in the Functional Behaviour Assessment", Journal of innovation in health informatics, vol. 25, no. 2, pp. 63-70.

[13] J. Horner, rApache: Web application development with R and Apache, 2012. Retrieved from http://www.rapache.net.

[14] D. Hardt, The OAuth 2.0 authorization framework (No. RFC 6749), 2012.

[15] D. B. Allison, and B. S. Gorman, "Calculating effect sizes for meta-analysis: The case of the single case", Behaviour Research and Therapy, vol. 31, no. 6, pp. 621-631, 1993.

[16] R. I. Parker, K. J. Vannest, J. L. Davis, and S. B. Sauber, S. B., "Combining nonoverlap and trend for single-case research: Tau-u”, Behavior Therapy, vol. 42, no. 2, pp. 284-299, 2011.

[17] A. Chifari, Guida al disturbo da deficit di attenzione e iperattività. Palermo: University Press, 2016. 